Open Access

\title{
Ambidextrous leadership, ambidextrous employee, and the interaction between ambidextrous leadership and employee innovative performance
}

Faris Alghamdi

Correspondence: fsaleh@bu.edu.sa Albaha University, Al Bahah, Saudi Arabia

\begin{abstract}
Leader opening and closing behaviors are assumed to foster high levels of employee exploration and exploitation behaviors, hence motivating employee innovative performance. Applying the ambidexterity theory of leadership for innovation, results revealed that leader opening and closing behaviors positively predicted employee exploration and exploitation behaviors, respectively, above and beyond the control variables. Moreover, results showed that employee innovative performance was significantly predicted by leader opening behavior, leader closing behavior, and the interaction between leaders' opening and closing behaviors, above and beyond control variables.
\end{abstract}

Keywords: Ambidextrous leadership, Ambidextrous employee, Employee innovative performance

\section{Background}

Over the last decade, there has been an enormous interest in theory and research on organizational ambidexterity. Long-term development and success rely on the organization's ability to exploit its current competencies while simultaneously exploring essentially new competencies. Organizations are constantly facing accelerating macro- and microlevel environmental changes, challenging to become dynamic and adapt to the unstable and heterogeneous context. Therefore, it is crucial for organizations to continuously adapt to external threats and opportunities and react with innovations and structural alignments. Organizational literature claimed that successful organizations within dynamic environments are ambidextrous which are aligned and efficient in the present while adaptable to future changes (Kauppila and Tempelaar 2016; Taródy 2016; Cao et al. 2009).

Researchers have claimed that ambidexterity is not only a significant antecedent of innovation at the organizational level, but also teams and individual workers have to deal with the tension between exploration and exploitation to be innovative. Leadership has been considered to be one of the most influential predictors of worker innovation and organizational development (Zacher et al. 2016; Hunter et al. 2011; Bledow et al. 2009). It has been argued that leaders have to encourage both exploration and exploitation behaviors among their employees, and hence the combination of high levels of both employee

(c) The Author(s). 2018 Open Access This article is distributed under the terms of the Creative Commons Attribution 4.0 International License (http://creativecommons.org/licenses/by/4.0/), which permits unrestricted use, distribution, and reproduction in any medium, provided you give appropriate credit to the original author(s) and the source, provide a link to the Creative Commons license, and indicate if changes were made. 
exploration and exploitation behaviors should result in high innovative performance (Rosing et al. 2011). The ambidexterity theory of leadership for innovation posits that leaders who engage in ambidextrous leadership behavior, i.e., opening and closing, are complementary with innovation requirements due to the fact that they encourage exploration and exploitation behaviors in an individual worker and a group (Zacher and Rosing 2015; Rosing et al. 2011). It is said that in order to be ambidextrous, workers should be able to explorative and exploitative simultaneously in equal amounts. Ambidexterity at an individual level is not only a possible level at which an organization can balance both exploration and exploitation behaviors, but is also needed for combining and gaining synergies between exploration and exploitation activities at a higher organizational level. March's analysis of two interrelated modes of strategic organizational option, i.e., exploration and exploitation can be deployed in a way where management deals with not only an organization as a whole, but also an individual worker pertain to that whole (Costea et al. 2012; Raisch et al. 2009; Levinthal and March 1993; March 1991).

So far, to the best of my knowledge, there has been no such empirical research in southern Saudi Arabia to examine the core proposition of ambidexterity theory of leadership for innovation. Moreover, despite the fact that individual ambidexterity is widely recognized, research devoted to examine ambidexterity at an individual level of analysis is still very scantly (Kauppila and Tempelaar 2016). Therefore, the current study examines the association between two elements of ambidextrous leadership, i.e., opening and closing leadership behaviors, and two elements of employees' ambidextrous behavior, i.e., exploration and exploitation behaviors, respectively, and the interaction between leader opening and closing behaviors and their influence on employee innovative performance.

\section{Literature review}

\section{Ambidextrous leadership}

The roots of ambidexterity, as an organizational concept, are well recognized. Duncan (1976) first coined the term organizational ambidexterity in the context of duality of organization's structures to support innovation. Twenty years later, the idea gained prominence in organizational learning by March (1991) and Tushman and O’Reilly III (1996). They suggested two modes of organizational learning exploration and exploitation by which organizations could utilize their resources. Ambidexterity refers to the ability of an organization to simultaneously engage in exploitation of current organizational capabilities and exploration of future opportunities. Exploitation is concerned with refinement, efficiency, selection, and implementation, whereas exploration is concerned with search, variation, experimentation, discovery (Ketkar and Puri 2017; Birkinshaw and Gupta 2013). This definition requires an organization to deal well with two conflicting elements: efficiency and flexibility (Adler et al. 1999), evolutionary and revolutionary change (Tushman and O'Reilly III 1996), low cost strategy with differentiation (Porter 1996), incremental and radical innovation, and the alignment of existing resources while becoming adapted to a changing environment at the same time (Gibson and Birkinshaw 2004).

The organizational ambidexterity was defined through two forms, namely structural ambidexterity and contextual ambidexterity. The former obtained through structural interventions and is based on the idea of a trade-off, which attained by outlining activities pertaining to exploration and exploitation (separation of exploration and exploitation into 
independent units with a leadership-integration and coordination at the top of an organization, while the latter requires exploitation of a current capability and exploration of a future opportunity (Ketkar and Puri 2017; Taródy 2016). This can be done by creating an organizational context, allowing organizational employees to engage in both explorative and exploitative behaviors and to determine autonomously how divide time and energy between both behaviors (Rosing and Zacher 2017; Gibson and Birkinshaw 2004). The ambidexterity theory of leadership for innovation (Rosing et al. 2011) posits that ambidextrous leadership includes three elements: opening leadership behavior to encourage explorative behavior, closing leadership behavior to encourage exploitative behavior, and flexibility over time to switch between both behaviors once a situation entails.

Opening leadership behavior is referred to leader behavior that increases variance in subordinates' behaviors through encouraging them to do things differently and to experiment, giving subordinates' opportunity for autonomous thinking and executing, and underpinning subordinates' attempts to contest a current situation. Hence, the ambidexterity theory of leadership for innovation claims that opening leadership behavior results in subordinates exploration activities. On the other hand, Closing leadership behavior is defined as leader behavior that decreases variance in subordinates' behaviors through taking corrective actions, putting specific guidelines, and monitoring goal attainment. Therefore, the ambidexterity theory of leadership for innovation claims that opening leadership behavior results in subordinates exploitation activities (Zacher and Rosing 2015; Rosing et al. 2011).

Having combined two forms of leadership behaviors, ambidextrous leadership defines as "the ability to foster both explorative and exploitative behaviors in followers by increasing or reducing variance in their behavior and flexibly switching between those behaviors. That is, ambidextrous leader are able to support their followers in the attempt to be ambidextrous" (Rosing et al. 2011, p. 957). Opening and closing leadership behavior are pertained to, yet different from, concept of transformational leadership. Transformational leaders might communicate an opening vision, concentrating on experimentation and developing breakthrough innovations, or they might communicate a closing vision, seeking to attain specific and clear-cut objectives (Zacher and Rosing 2015). Nevertheless, ambidextrous leaders engage in complex cognitive processes (Mom et al. 2015) such as integrative or paradoxical thinking (Martin 2007; Smith and Tushman 2005) to accommodate the tensions that are likely to come out when pursuing a sort of diverse opportunities, goals, and needs. They may conflict as for time horizon (O'Reilly 3rd and Tushman 2004), risk profile (March 1991), link to the present strategy (Probst et al. 2011; Andriopoulos and Lewis 2009), and leader's responsibilities (Floyd and Lane 2000).

\section{Employee ambidexterity}

At the employee level, i.e., human side, exploitative activities include utilizing current knowledge and skills to make short-run improvements to efficiency and effectiveness. On the other hand, explorative activities comprise behaviors such as seeking out for new product and process innovation as well as for competitive solutions and behaviors. That require employees to learn new skills or knowledge and adapt present routines. Both exploitation and exploration are learning-related activities. Employee ambidexterity is a multidimensional construct refers to behavioral orientation of employees to combine exploitation and exploration associated activities in a definite period of time (Caniëls and 
Veld 2016; Kang and Snell 2009; Gibson and Birkinshaw 2004). Instead of being a psychological trait, ambidexterity is an individual behavioral capability to engage in and rotate between paradoxal task elements (Kauppila and Tempelaar 2016).

According to Gupta et al. (2006), an individual level is said to be the level at which ambidexterity is most difficult to achieve. However, in order to balance exploitation and exploration, employees have to get the intellectual, social and physical capacity, will, strength, and ability to produce, carry out, and refine current rules and routines. Likewise, they are required to have the intellectual, social and physical capacity, will, strength, and ability to conduct an experiment, search, and manipulate new rules and routines to focus on and interpret an environment, that therefore entails ideal employees not to be only submissive organizational workers in the way that they carry out regulated rules and routines; rather they should also be an entrepreneur in exploring new rules and routines within an organizational environment (Holmqvist and Spicer 2012).

Employee ambidexterity encompasses distinct dimensions of exploration and exploitation (Mom et al. 2007), hence can be boosted via any factor that increase exploration and exploitation. It should be noted that this increase is not at the expense of reducing the other, i.e., is not mutually exclusive. According to Caniëls and Veld (2016), combining explorative and exploitative activities yields three situations: a balanced situation, in which explorative and exploitative activities are equally present or absent; an unbalanced situation, in which explorative activities exceed exploitative activities; and an unbalanced situation exploitative activities exceed explorative activities. In the same vein, Good and Michel (2013) took a cognitive perspective of employee ambidexterity and argued that to attain ambidexterity, employees have to be able to flexibly rotate either simultaneous or rapidly sequential between exploration and exploitation in environments that are changing.

\section{Employee innovative performance}

Innovation is a heterogeneous construct, indicating to at least two processes. The first process is the generation of new and useful ideas. The second process is the implementation of these ideas. Employee innovative performance refers to the proficiency of employee behaviors designed for innovative outcome, comprising the generation and carrying out novel and beneficial ideas. it is different from creativity in the way that it involves not only the generation but also the execution of ideas. Although creativity is very much related to innovation, creativity is only a starting point (Rosing and Zacher 2017; Baer 2012).

Literatures regarding employee innovation performance suggested that all types of innovation start with the first phase, the generation of ideas, in which novel and useful ideas can be generated in any domain. The second phase is idea development, in which building a coalition of supporters and obtaining approvals for ideas are sought from colleagues and/or managers. The last phase is idea realization, in which these ideas transform into useful applications within a work role or group, or within the whole organization. It should be noted that employee innovation performance is a multistage process with different activities, different stages of development, and different employee behaviors needed for each stage. Since employee innovation performance is described as discontinued activities rather than discrete, sequential stages, employees are likely to involve in any combination of these behaviors at any time (Abbas and Raja 2015; Scott and Bruce 1994). Simple innovations can be often done by employees involved, whereas 
attaining more complex innovations usually entails joint effort, i.e., teamwork based upon a range of precise knowledge, competence, and work roles (Janssen 2000).

\section{Hypothesis development}

Organizational scholars have claimed that innovation is a function of individual factors such as cognitive abilities, personality, and motivation, as well as contextual factors such as work characteristics, organizational culture, and leadership. Some studies (g., Eisenbeiss et al. 2008; Mumford et al. 2002; Tierney and Farmer 2002) concluded that leadership is one of the most significant antecedents of innovation (Zacher and Rosing 2015). The ambidexterity theory of leadership for innovation implied that leaders have to display a combination of two kinds of behaviors to improve employee innovative performance, namely opening and closing behaviors. The former includes actions that drives employee exploration, such as promoting alternative methods for task achievement, autonomous thinking, and allowing for errors. The later concerns with actions that ease exploitation of ideas, such as setting up routines and monitoring goal attainment, and ensuring that rulers are followed (Zacher and Wilden 2014).

Employee ambidexterity is conceptualized as the combination of employee exploration and exploitation (Rosing and Zacher 2017; Mom et al. 2007). Studies implied that employees behave ambidextrously to the degree that their supervisors show a leadership style that is planned to ease explorative and exploitative activities in their subordinates. Combining leadership behaviors that encourage employee exploration and exploitation allow leaders to build an environment that welcome paradoxical thanking in which employees' exploration and exploitation are equally linked facets of their work role. Paradoxical leadership-a leadership style that combining leader behaviors that promote employee explorative behaviors with leader behaviors that promote employee exploitative behaviors-is effective in fostering employee ambidexterity since it combines different leader behaviors, and hence matches employee explorative and exploitative behaviors simultaneously. Paradoxical leadership educes exploitative behaviors through communicating leaders' high expectations of their subordinates' job performance while promoting explorative behaviors through creating a support organizational environment that motivates experimentation and tolerance errors of their subordinates (Kauppila and Tempelaar 2016; Gibson and Birkinshaw 2004).

Leader-member exchange (LMX) theory posits that leadership behaviors depends upon relationships with subordinates. Given that, high quality exchange relationships are described as reciprocal trust and respect, and hence positively related to creativity-more closely to exploration-and innovation, which more closely to exploitation. This perspective is in line with (Rosing et al. 2011) who proposed that opening leader behaviors are positively related to employee explorative activities, and closing leader behaviors are positively related to employee exploitative activities. Finally, an empirical study by Zacher et al. (2016) revealed that leader opening behaviors positively predicted employee exploration behavior above and beyond some control variables, and closing leader behaviors positively predicted employee exploitation behavior above and beyond some control variables. Based on the preceding discussion, the following hypotheses are proposed (Fig. 1):

H1: There is a positive relationship between leader opening behavior and employee exploration behavior. 


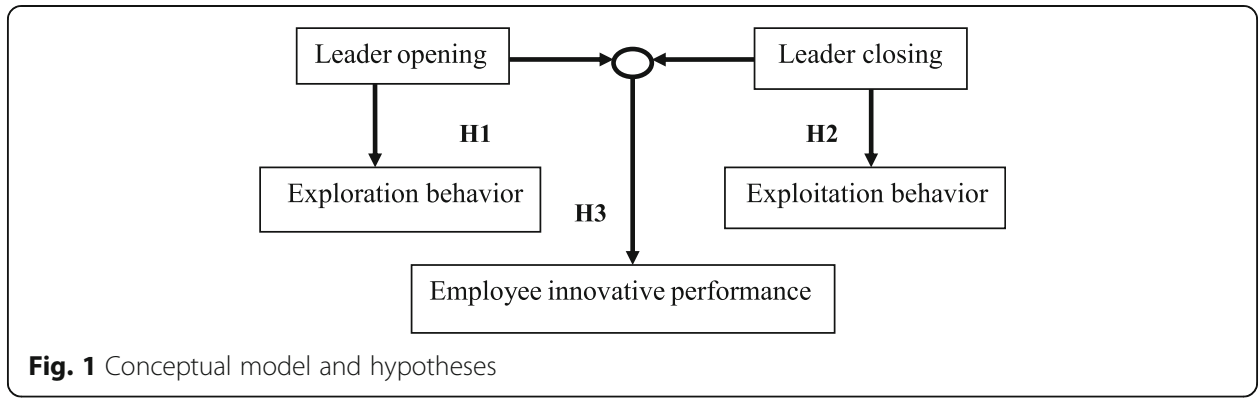

H2: There is a positive relationship between leader closing behavior and employee exploitation behavior.

The interaction between opening and closing behaviors that predicts employee innovative performance is the essence postulation of ambidexterity theory of leadership for innovation, in that employee innovative performance is highest when opening and closing behaviors are high. It is a direct situation in a way that high closing behavior allows a positive effect of opening behavior on employee innovative performance; at the same time high opening behavior allows a positive effect of closing behavior on employee innovative performance. Facilitating of process when employees turn their creative ideas-primarily stimulated through leaders' opening behavior-into innovative products or services is a function of leaders' high closing behavior. Likewise, employee innovative performance is likely to be lower when leaders engage only in either high opening or high closing behaviors. Combining high opening and low closing behaviors are not likely to generate high employee innovative performance due to the fact that leaders do not motivate employees to carry out their creative ideas. However, combining low opening and high closing behaviors are not likely to produce high employee innovative performance since employees are not initially motivated by leaders to create creative ideas, and hence they will not take advantage of closing behavior as to their innovative performance. Finally, employee innovative performance will be low whenever opening and closing behavior are low (Rosing et al. 2011; Zacher and Wilden 2014; Zacher and Rosing 2015; Zacher et al. 2016). Based on the preceding discussion, the following hypothesis is proposed:

H3: The interaction between leaders' opening and closing behaviors predicts employee innovative performance insofar employee innovative performance is highest when both opening and closing leadership behaviors are high.

\section{Methods}

\section{Participants and procedure}

To test study's hypotheses, data were collected from faculties of colleges of a public university in Albaha province. The survey was accompanied by a cover letter explaining the purpose of the study and an assurance of confidentiality and anonymity. In the letter were instructions for completing and returning the survey with one week to the dean of college of applied studies and continuing education. Excluding demographic variables, the survey was translated from English language to Arabic language, which is the official language for all potential participants, using a back-translation technique. In doing so, a professor at Albaha University translated the original questionnaire into Arabic language 
and then another professor at the same university translated back to English language without references to the original English version. Both professors are fully bilingual. After that, the researcher went carefully over both versions and made revisions needed in order to ensure a complete and accurate meaning of the original text of the questionnaire. In addition, the researcher wanted to enhance ease of use and readability and an appropriate level of formality.

The current study used a self-report questionnaire administered to 400 faculty members at the end of August 2017, and 147 responses were received, with a response rate of 37\%. Of the respondents, 64.6 were male, $49 \%$ were in the range from 40 to 50 years old, and most of respondents (55.8\%) were assistance professor. The majority of respondents $(85.7 \%)$ received a doctorate degree.

\section{Measures}

This study applied a descriptive cross-sectional method. The study instrument is structured, self-administered, and comprises four parts. The first part included items regarding demographic characteristics of participants, namely age, gender, educational level, and faculty positions. Faculty members reported their age in years, their gender $(0=$ female and $1=$ male), educational level ( 1 = bachelor degree, $2=$ master degree, $3=$ doctorate degree $)$, and faculty positions ( 1 = full professor, 2 = associate professor, 3 = assistance professor, $4=$ lecturer, 5 = teaching assistance).

The second part is ambidextrous leadership that includes two dimensions: opening and closing leadership behaviors. The former dimension was measured using 7-item scale and the later was measured using 6-item scale. Both scales were developed by Rosing et al. (2011). Faculty members were asked to rate their supervisor's leadership behaviors using two sets of items. Cronbach's alphas for two scales were .85 for leader opining behavior and.74 for leader closing behavior. The items were answered on a 5-point scale ranging from 1 (not at all) to 5 (always). An exploratory factor analysis with Varimax rotation revealed that the items had highest factor loadings on their theoretically pertinent factor. This indicates that faculty members differentiated between opening or closing behaviors in their ratings.

The third part is ambidextrous employee that comprises two dimensions, namely exploration and exploitation behaviors. The former dimension was measured with 5item scale and the later was measured with 6-item scale. Both scales were developed and validated by Mom et al. (2007). Faculty members rated the extent to which they engaged in two sets of behaviors on a 5-point Likert scale ranging from 1 (strongly disagree) to 5 (strongly agree). Cronbach's alphas for two scales were .85 for exploration behavior and .83 for exploitation behavior. The fourth part is employee innovative performance that was measured with 4-item scale. This scale was developed and validated by Welbourne et al. (1998). Faculty members were asked to rate their own innovative performance at work on a 5-point scale ranging from 1 (need much improvement) to 5 (excellent). Cronbach's alpha for this scale was .84 .

\section{Data analysis}

The study hypotheses were assessing using hierarchical regression analysis and simple slope analysis (Cohen et al. 2013). In the first two analyses predicting employee exploration and exploitation behaviors, the demographic variables were entered in the first step, and leader 
opening and closing behaviors were entered in the second step in the regression equations. In the third analysis predicting employee innovative performance, the interaction of leader opening and closing behaviors was entered in the third step. The interaction was probed using simple slope analysis. Hence, employee innovative performance was regressed on leader opening behaviors at high (1 SD above the mean) and low (1 SD below the mean) levels of leader closing behaviors.

Prior to theses analyses, confirmatory factor analyses were performed in order to examine the factor structure of the self-report items used to measure the five central constructs of the current study, namely opening leadership behavior, closing leadership behavior, employee exploration behavior, employee exploitation behavior, and employee innovative behavior. It is assumed that an adequate fit of the factor models can be archived when a comparative fit index (CFI) of .90 or higher and a root-mean square error of approximation (RMSEA) of .08 or lower (Avery et al. 2007).

As shown in Table 1., the hypothesized measurement model (Model 1) is a significantly $(P<.001)$ better fit than any of the alternative models. The fit indices reveal that the hypothesized 5 -factor model fits that data satisfactorily such that all items loaded significantly on $(P<.001)$ on their designated latent constructs. Moreover, a 6-factor model was tested to assess possible concerns about common method bias when using self-report scales. In this model, the five scales' indicators had equal factor loadings on an additional latent method factor. The method effects model had no considerably improve the fit beyond the 5 -factor model $\left(X^{2}[339]=555.629, P<.001\right.$; CFI $=.89$; RMSEA $\left.=.066\right)$. Therefore, these findings propose that common method bias was not a significant problem (Podsakoff et al. 2012).

\section{Results}

The descriptive statistics and correlations of study variables are shown in Table 2. Opening leadership behavior associated positively and significantly with closing leadership behavior $(r=.64, P<.01)$. Also, opening leadership behavior associated positively and significantly $(r=.41, P<.01)$ with employee exploration behavior, employee exploitation behavior $(r=.42, P<.01)$, and employee innovative behavior $(r=.44, P<.01)$. The positive and significant relationship between opening leadership behavior and employee exploration behavior gives initial support for hypothesis 1 .

Moreover, closing leadership behavior was positively and significantly associated with employee exploration behavior $(r=.37, P<.01)$, employee exploitation behavior $(r=.45$,

Table 1 Comparison of measurement models

\begin{tabular}{|c|c|c|c|c|c|c|}
\hline Model & Factor & $x^{2}$ & $\mathrm{dF}$ & $\mathrm{CFI}$ & RMSEA & $P$ \\
\hline 1. & $\begin{array}{l}\text { 5-factor: LOB, LCB, ERB, EIB, EIP } \\
\text { All items loaded on their designated factors. }\end{array}$ & 570.59 & 340 & .89 & .07 & .000 \\
\hline 2. & $\begin{array}{l}\text { 3-factor: LOB and LCB items loaded on the same } \\
\text { factor, ERB and FIB items loaded on the same } \\
\text { factor, and EIP loaded on third factor. }\end{array}$ & 648.22 & 349 & .85 & .07 & .000 \\
\hline 3. & $\begin{array}{l}\text { 2-factor: LOB and LCB items loaded on the same } \\
\text { factor and ERB, FIB, and EIP items loaded on the } \\
\text { same factor. }\end{array}$ & 742.32 & 352 & .81 & .09 & .000 \\
\hline 4. & $\begin{array}{l}\text { 1-factor: LOB, LCB, ERB, EIB, EIP items loaded on } \\
\text { a single factor. }\end{array}$ & 1144.2 & 350 & .62 & .13 & 000 \\
\hline
\end{tabular}

$\angle O B$ leader opening behavior, $L C B$ leader closing behavior, ERB employee exploration behavior, EIB employee exploitation behavior, EIP employee innovative performance 
Table 2 Means, standard deviations, and correlations among variables ( $N=147)$

\begin{tabular}{|c|c|c|c|c|c|c|c|c|c|c|}
\hline & $M$ & SD & 1 & 2 & 3 & 4 & 5 & 6 & 7 & 8 \\
\hline Age & 2.9 & .75 & & & & & & & & \\
\hline $\mathrm{EdL}$ & 2.8 & .54 & $.41^{* *}$ & & & & & & & \\
\hline Gen & .67 & .52 & $.24^{* *}$ & $.25^{* *}$ & & & & & & \\
\hline $\mathrm{FaP}$ & 2.8 & .99 & $-.60^{* *}$ & $-.73^{* *}$ & $-.31^{* *}$ & & & & & \\
\hline LOB & 3.6 & .77 & .07 & .16 & .02 & $-.17^{*}$ & & & & \\
\hline LCB & 3.9 & .62 & .03 & .11 & -.07 & -.14 & $.64^{* *}$ & & & \\
\hline ERB & 4.4 & .59 & .02 & .13 & $-.18^{*}$ & -.13 & $.41^{* *}$ & $.37^{* *}$ & & \\
\hline $\mathrm{EIB}$ & 4.3 & .52 & -.03 & .08 & $-.20^{*}$ & -.08 & $.42^{* *}$ & $.45^{* *}$ & $.75^{* *}$ & \\
\hline EIP & 4.2 & .64 & .11 & $.21^{*}$ & $-.17^{*}$ & $-.21^{*}$ & $.46^{* *}$ & $.42^{* *}$ & $.62^{* *}$ & $.55^{* *}$ \\
\hline
\end{tabular}

$P<.01)$, and employee innovative behavior $(r=.42, P<.01)$. The positive and significant relationship between closing leadership behavior and employee exploitation behavior gives initial support for hypothesis 2 . Finally, employee exploration behavior was positively and significantly associated with employee exploitation behavior $(r=.75, P<.01)$ and employee innovative performance $(r=.62, P<.01)$. Employee exploitation behavior was positively and significantly associated with employee innovative performance $(r=.55, P<.01)$.

The findings of three regression analyses performed to test study hypotheses are shown in Table 3. Leader opening behavior positively predicted employee exploration behavior above and beyond the control variables $(\beta=.29, P<.01)$. Hence, hypothesis 1 was supported. Also, employee exploration behavior was predicted by gender $(\beta=-.21, P<.01)$.

As for hypothesis 2 , Leader closing behavior positively predicted employee exploitation behavior above and beyond the control variables $(\beta=.26, P<.01)$. Hence, hypothesis 2 was supported. Moreover, employee exploitation behavior was predicted by gender $(\beta=-.21, P<.01)$ and leader opening behavior $(\beta=.25, P<.05)$.

Hypothesis 3 states that the interaction between leaders' opening and closing behaviors predicts employee innovative performance, insofar employee innovative performance is highest when both opening and closing leadership behaviors are high. Results in Table 3 reveal that employee innovative performance was significantly predicted by leader opening behavior $(\beta=.37, P<.01)$, leader closing behavior $(\beta=.26, P<.01)$, and interaction between leaders' opening and closing behaviors $(\beta=.26, P<.01)$, above and beyond control variables. This interaction was probed using simple slope analysis that is illustrated in Fig. 2. It revealed that the association between leader opening behavior and employee innovative behavior was stronger when leader closing behavior was high $(\beta=.37, P<.01)$ than when leader closing behavior was low $(\beta=.23, P<.05)$. Hence, hypothesis 3 is supported.

\section{Discussion}

The current study is the first of its kind to investigate ambidexterity theory of leadership for innovative in Saudi Arabia, particularly in southern region, at the individual employee level (Rosing et al. 2011; Rosing and Zacher 2017). The findings showed that the relationship between leader opening behavior and employee exploration behavior was positive and statistically significant above and beyond the effects of control variables. Also, the 
Table 3 Results of hierarchical regression analysis

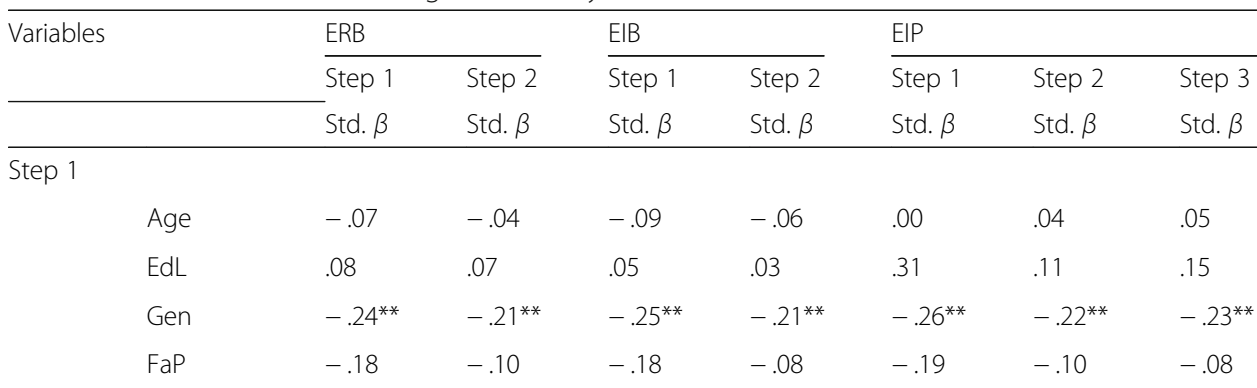

Step 2

$\begin{array}{lllll}\text { LOB } & .29^{* *} & .25^{*} & .32^{* *} & .37^{* *} \\ \text { LCB } & .15 & .26^{* *} & .17 & .26^{* *}\end{array}$

Step 3

\begin{tabular}{|c|c|c|c|c|c|c|c|}
\hline$L O B^{*} L C B B$ & & & & & & & $.26^{* *}$ \\
\hline$\Delta R^{2}$ & $.08^{*}$ & $.16^{* *}$ & $.07^{*}$ & $.20^{* *}$ & $.11^{* *}$ & $.20^{* *}$ & $.05^{* *}$ \\
\hline$R^{2}$ & .08 & .24 & 0.7 & .27 & .11 & .31 & .35 \\
\hline$F$ & $2.95^{*}$ & $7.26^{* *}$ & $2.66^{*}$ & $8.79^{* *}$ & $4.30^{* *}$ & $10.22^{* *}$ & $10.89^{* *}$ \\
\hline
\end{tabular}

The results of variance inflation factor (VIF) did not show any problems of multicollinearity. Predictor variables were centered ${ }^{*} P<05$

${ }^{* * P} P<01$

relationship between leader closing behavior and employee exploitation behavior was positive and statistically significant above and beyond the effects of control variables. These findings are consistent with ambidextrous leadership theory (Rosing et al. 2011). According to this theory, leader opening behaviors-increasing variance in follower behaviors through motivating them to do things differently and to experiment, giving follower a chance for independent thinking and acting, as well as supporting follower's endeavor to change the current situation-predict employee exploration behaviors, whereas leader closing-reducing variance in follower behaviors through taking corrective action, setting exact guidelines, and monitoring goal attainment-predict employee exploitation behaviors. These findings are also in line with previous studies (Zacher and Rosing 2015; Zacher and Wilden 2014; Zacher et al. 2014) in that leader opening and closing behaviors positively predict employees' exploration and exploitation behaviors, at individual and team levels of analysis.

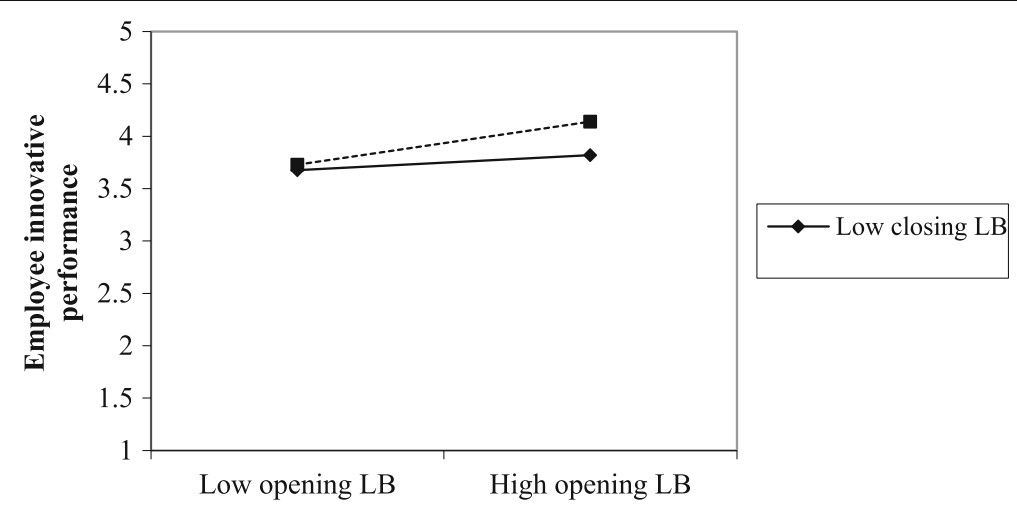

Fig. 2 Interactive effect of LOB and LCB on EIP 
It is impotent to point out that although the present study was undertaken in a nonWestern culture, i.e., Saudi Arabia, it had similar results with earlier studies conducted in Western cultures(Zacher and Rosing 2015; Zacher and Wilden 2014; Zacher et al. 2014). It may attribute to the fact that the definition (i.e., behaviors, actions, styles, and philosophies) of leadership in a non-western perspective is similar to the definition of leadership in a Western perspective. Leadership in a non-Western culture i.e., Islamic perspective refers to a process of inspiring and coaching voluntary followers in an effort to accomplish a clear as well as shared vision. Likewise, within Western cultures, transformational leaders are "moving the follower beyond immediate self-interests through idealized influence (charisma), inspiration, intellectual stimulation, or individualized consideration". (Bass 1999, P.11; Altalib 1991). It has been claimed that transformational and transactional leadership theories will have a universal application as these theories have the capacity to be modified in various cultural environments (Avolio and Bass 2004).

Unexpectedly, findings of this study showed that women were significantly more likely to engage in exploration $(M=4.49, P<.05)$ and exploitation $(M=4.44, P<.05)$ behaviors than their male counterparts. In addition, Female were significantly more innovative $(M=4.33$, $P<.05$ ) than their male counterparts. According to masculinity-femininity (Hofstede and Minkov 2010) dimension of national cultures, Saudi Arabia is a masculine society where men are more dominate in almost every aspect of social life. Religious, cultural and social factors play an important role in the position of women, preserving women's status and verifying their position as subordinate remembers of society. This contradictory situation between the findings and the explanation of women's status in Saudi Arabia may account for the recent efforts from Saudi government to empower women and give them more opportunities to participate effectively in the social life, including workplace settings (Hodges and Hodges 2017). It is witnessed that Saudi women being able to take more responsibility in public spheres and occupy higher positions in organizations (Thompson 2015).

Finally, the results of the current study revealed that employee innovative performance was significantly predicted by leader opening behavior, leader closing behavior, and interaction between leaders' opening and closing behaviors above and beyond control variables.. It showed that employee innovative performance was highest when both leader opening behavior, leader closing behaviors were high. This findings are consistent with the core assumption of the ambidexterity theory of leadership for innovation (Rosing et al. 2011) and previous studies (Zacher and Rosing 2015; Zacher and Wilden 2014) suggesting that the positive relationship between leader opening behavior and employee innovative performance can be further augmented through high leader closing behavior. It is claimed that leader closing behavior such as establishing routines monitoring goals accomplishment, taking corrective actions should enhance the positive association between leader opening behavior and employee innovative performance, resulting in new and improved products and services that are beneficial for sustainable social, cultural, and economic development.

\section{Conclusions}

This study contributes to the ambidexterity literature by applying the ambidexterity theory of leadership for innovation to participants from a non-Western culture at an individual level. It is the first of its kind to be undertaken in a non-Western culture, Saudi Arabia, particularly in the southern region. The second major contribution of the current study to the ambidexterity research is that researchers can apply the ambidexterity theory 
of leadership for innovation to non-Western cultures since the survey, which was developed in a Western culture, showed good psychometric properties. This was confirmed by results of examining the study hypotheses that were consistent with the ambidexterity theory of leadership for innovation as well as previous studies conducted in Western cultures.

Leader opening and closing behaviors at a high level can generate employee exploration and exploitation behaviors at a high level. However, in a situation where either employee exploration or exploitation behaviors, or both, are low, leader opening and closing behaviors would be at a low level accordingly, which in turn, resulting in a low level of employee innovative performance. It is a believed that employees would engage in exploration and exploitation behaviors when leadership styles are stimulating their exploration behaviors and facilitating their exploitation of ideas. Finally, it is very crucial that leaders should be flexible to switch between leader opening behaviors to be foster creativity and generate ideas, and leader closing behaviors to ensure high levels of efficiency and productivity. Leader opening and closing behaviors at a high level would improve employee innovative performance at a high level, hence influencing employee's decision process, psychological well-being, and future creative and innovative outcomes. It is recommended that organizations should build a culture of innovation wherein leadership styles foster both exploration and exploitation behaviors among their subordinates at a high level, and hence leading to high employee innovative performance. It is also recommended that organizations should concentrate on two important factors to influence employee innovative performance, namely organizational factor such as supporting environment, autonomy, and freedom, as well as individual factors or personal characteristics such as self-belief and intrinsic and extrinsic motivations. These should be gained through training leaders in ambidextrous leadership behaviors and through encouraging exploration and exploitation behaviors among employees.

This study cannot go without some limitations that need to be addressed in the future research. First, given that this study did not control for some important variables such as autonym, self-belief and intrinsic and extrinsic motivations, self-belief, and supporting environment that are said to be influence employee innovative performance, future research should include these variables when study the ambidexterity theory of leadership for innovation. Second, to claim causality, cross-sectional study should be replaced with longitudinal study. Finally, employee innovative performance was not measure in an objective way such as number of new ideas in a certain time, R\&D output index, and invention patent quantity, and hence these objective measures should be used.

Acknowledgements

I thank the anonymous reviewers for their careful reading of our manuscript and their many insightful comments, as these comments led to an improvement of the manuscript.

Funding

I received no specific funding for this manuscript.

Availability of data and materials

Data and material are available at any time. There are no restrictions on the availability of data and material.

Authors' contributions

I have full contributions to this manuscript. The author read and approved the final manuscript. 


\section{Publisher's Note}

Springer Nature remains neutral with regard to jurisdictional claims in published maps and institutional affiliations.

Received: 17 January 2018 Accepted: 7 February 2018

Published online: 17 February 2018

\section{References}

Abbas, M, \& Raja, U. (2015). Impact of psychological capital on innovative performance and job stress. Canadian Journal of Administrative Sciences/Revue Canadienne des Sciences de l'Administration, 32(2), 128-138.

Adler, PS, Goldoftas, B, Levine, DI. (1999). Flexibility versus efficiency? A case study of model changeovers in the Toyota production system. Organization Science, 10(1), 43-68.

Altalib (1991). Training guide for Islamic workers. Herndon, VA: IIIT\&IIFSO.

Andriopoulos, C, \& Lewis, MW. (2009). Exploitation-exploration tensions and organizational ambidexterity: managing paradoxes of innovation. Organization Science, 20(4), 696-717.

Avery, DR, McKay, PF, Wilson, DC. (2007). Engaging the aging workforce: the relationship between perceived age similarity, satisfaction with coworkers, and employee engagement. Journal of Applied Psychology, 92(6), 1542-1556.

Avolio, B, \& Bass, B (2004). Multifactor leadership questionnaire. Menlo Park, CA: Mind Garden.

Baer, M. (2012). Putting creativity to work: the implementation of creative ideas in organizations. Academy of Management Journal, 55(5), 1102-1119.

Bass, BM. (1999). Two decades of research and development in transformational leadership. European Journal of Work and Organizational Psychology, 8(1), 9-32

Birkinshaw, J, \& Gupta, K. (2013). Clarifying the distinctive contribution of ambidexterity to the field of organization studies. The Academy of Management Perspectives, 27(4), 287-298.

Bledow, R, Frese, M, Anderson, N, Erez, M, Farr, J. (2009). A dialectic perspective on innovation: conflicting demands, multiple pathways, and ambidexterity. Industrial and Organizational Psychology, 2(3), 305-337.

Caniëls, MC, \& Veld, M (2016). Employee ambidexterity, high performance work systems and innovative work behavior: how much balance do we need? The international journal of human resource management (pp. 1-21).

Cao, Q, Gedajlovic, E, Zhang, H. (2009). Unpacking organizational ambidexterity: dimensions, contingencies, and synergistic effects. Organization Science, 20(4), 781-796.

Cohen, J, Cohen, P, West, SG, Aiken, LS (2013). Applied multiple regression/correlation analysis for the behavioral science. NY: Routledge.

Costea, B, Amiridis, K, Crump, N (2012). In pursuit of the ambidextrous graduate: potentiality between exploration and exploitation. In M Holmqvist, A Spicer (Eds.), Research in the Sociology of Organizations, Emerald, (pp. 53-74).

Duncan, R. B. (1976). The ambidextrous organization: Designing dual structures for innovation. The Management of Organization, 1, 167-188.

Eisenbeiss, SA, van Knippenberg, D, Boerner, S. (2008). Transformational leadership and team innovation: integrating team climate principles. Journal of Applied Psychology, 93(6), 1438-1446.

Floyd, SW, \& Lane, PJ. (2000). Strategizing throughout the organization: managing role conflict in strategic renewal. Academy of Management Review, 25(1), 154-177.

Gibson, CB, \& Birkinshaw, J. (2004). The antecedents, consequences, and mediating role of organizational ambidexterity. Academy of Management Journal, 47(2), 209-226.

Good, D, \& Michel, EJ. (2013). Individual ambidexterity: exploring and exploiting in dynamic contexts. The Journal of Psychology, 147(5), 435-453.

Gupta, AK, Smith, KG, Shalley, CE. (2006). The interplay between exploration and exploitation. Academy of Management Journal, 49(4), 693-706.

Hodges, J, \& Hodges, J. (2017). Cracking the walls of leadership: women in Saudi Arabia. Gender in management: an international journal, 32(1), 34-46.

Hofstede, G, \& Minkov, GJM (2010). Cultures and organizations: software of the mind. New York, NY: McGraw-Hill.

Holmqvist, M., \& Spicer, A. (2012). The ambidextrous employee: Exploiting and exploring people's potential. In Managing 'Human Resources' by Exploiting and Exploring People's Potentials (pp. 1-23). Emerald Group Publishing Limited.

Hunter, ST, Thoroughgood, CN, Myer, AT, Ligon, GS. (2011). Paradoxes of leading innovative endeavors: summary, solutions, and future directions. Psychology of Aesthetics, Creativity, and the Arts, 5(1), 54-66.

Janssen, O. (2000). Job demands, perceptions of effort-reward fairness and innovative work behavior. Journal of Occupational and Organizational Psychology, 73(3), 287-302.

Kang, SC, \& Snell, SA. (2009). Intellectual capital architectures and ambidextrous learning: a framework for human resource management. Journal of Management Studies, 46(1), 65-92.

Kauppila, OP, \& Tempelaar, MP. (2016). The social-cognitive underpinnings of employees' ambidextrous behavior and the supportive role of group managers' leadership. Journal of Management Studies, 53(6), 1019-1044.

Ketkar, S, \& Puri, R (2017). Ambidextrous human resource practices and employee performance, Indian Institute of Technology Delhi (pp. 170-178)

Levinthal, DA, \& March, JG. (1993). The myopia of learning. Strategic Management Journal, 14(S2), 95-112.

March, JG. (1991). Exploration and exploitation in organizational learning. Organization Science, 2(1), 71-87.

Martin, RL. (2007). How successful leaders think. Harvard Business Review, 85(6), 60-67.

Mom, TJ, Fourné, SP, Jansen, JJ. (2015). Managers' work experience, ambidexterity, and performance: the contingency role of the work context. Human Resource Management, 54(S1), 1-21.

Mom, TJ, Van Den Bosch, FA, Volberda, HW. (2007). Investigating managers' exploration and exploitation activities: the influence of top-down, bottom-up, and horizontal knowledge inflows. Journal of Management Studies, 44(6), 910-931.

Mumford, MD, Scott, GM, Gaddis, B, Strange, JM. (2002). Leading creative people: orchestrating expertise and relationships. The Leadership Quarterly, 13(6), 705-750.

O'Reilly 3rd, CA, \& Tushman, ML. (2004). The ambidextrous organization. Harvard Business Review, 82(4), 74-81. 
Podsakoff, PM, MacKenzie, SB, Podsakoff, NP. (2012). Sources of method bias in social science research and recommendations on how to control it. Annual Review of Psychology, 63, 539-569.

Porter, ME. (1996). What is strategy? Harvard Business Review, 74, 61-78.

Probst, G, Raisch, S, Tushman, ML. (2011). Ambidextrous leadership: emerging challenges for business and HR leaders. Organizational Dynamics, 40(4), 326-334

Raisch, S, Birkinshaw, J, Probst, G, Tushman, ML. (2009). Organizational ambidexterity: balancing exploitation and exploration for sustained performance. Organization Science, 20(4), 685-695.

Rosing, K, Frese, M, Bausch, A. (2011). Explaining the heterogeneity of the leadership-innovation relationship: ambidextrous leadership. The Leadership Quarterly, 22(5), 956-974.

Rosing, K, \& Zacher, H. (2017). Individual ambidexterity: the duality of exploration and exploitation and its relationship with innovative performance. European Journal of Work and Organizational Psychology, 26(5), 694-709.

Scott, SG, \& Bruce, RA. (1994). Determinants of innovative behavior: a path model of individual innovation in the workplace. Academy of Management Journal, 37(3), 580-607.

Smith, WK, \& Tushman, ML. (2005). Managing strategic contradictions: a top management model for managing innovation streams. Organization Science, 16(5), 522-536.

Taródy, D. (2016). Organizational ambidexterity as a new research paradigm in strategic management. Vezetéstudomány/Budapest Management Review, 47(5), 39-52.

Thompson, MC. (2015). Saudi women leaders: challenges and opportunities. Journal of Arabian Studies, 5(1), 15-36.

Tierney, P, \& Farmer, SM. (2002). Creative self-eff: its potential antecedents and relationship to creative performance. Academy of Management Journal, 45(6), 1137-1148.

Tushman, ML, \& O'Reilly III, CA. (1996). Ambidextrous organizations: managing evolutionary and revolutionary change California Management Review, 38(4), 8-29.

Welbourne, TM, Johnson, DE, Erez, A. (1998). The role-based performance scale: validity analysis of a theory-based measure. Academy of Management Journal, 41(5), 540-555.

Zacher, H, Robinson, AJ, Rosing, K. (2016). Ambidextrous leadership and Employees' self-reported innovative performance: the role of exploration and exploitation behaviors. The Journal of Creative Behavior, 50(1), 24-46.

Zacher, H, \& Rosing, K. (2015). Ambidextrous leadership and team innovation. Leadership \& Organization Development Journal, 36(1), 54-68

Zacher, H, \& Wilden, RG. (2014). A daily diary study on ambidextrous leadership and self-reported employee innovation. Journal of Occupational and Organizational Psychology, 87(4), 813-820.

Submit your manuscript to a SpringerOpen ${ }^{\circ}$ journal and benefit from:

- Convenient online submission

- Rigorous peer review

Open access: articles freely available online

High visibility within the field

Retaining the copyright to your article

Submit your next manuscript at $>$ springeropen.com 